\title{
The decreasing trend in hip fractures: response to Stevens \& Rudd
}

\author{
E. Cassell • A. Clapperton
}

Received: 8 December 2013 / Accepted: 1 April 2014 /Published online: 17 April 2014

(C) International Osteoporosis Foundation and National Osteoporosis Foundation 2014

Dear editor,

We analysed the trends in fall-related hip fracture incidence for men and women separately by 10-year age groups (65 to 74, 75 to 84 and 85 years and older) to compare our results for Victoria [1] to those reported for the USA by Stevens and Rudd in their letter [2]. Our results showed that, from 1998/9 to 2008/9, fallrelated hip fracture rates for men and women decreased significantly in all 10-year age groups (range -43.1 to $-20.8 \%$ ). However, in contrast to the pattern found for the USA, the sharpest decline in hip fracture rates was in males aged 6574 years $(-43.1 \%, 95 \%$ confidence interval -51.2 to -35.5$)$, then in females in the same age group $(-28.1 \%, 95 \%$ confidence interval -39.4 to -15.7 ).

\section{References}

1. Cassell E, Clapperton A (2013) A decreasing trend in fall-related hip fracture incidence in Victoria, Australia. Osteoporos Int 24:99-109. doi:10.1007/s00198-012-1937-6

2. Stevens JA, Rudd RA (2014) Comment on Cassell and Clapperton: a decreasing trend in fall-related hip fracture incidence in Victoria, Australia. Osteoporos Int. doi:10.1007/s00198-013-2584-2 